\title{
IMPLEMENTATION OF GREEDY ALGORITHM IN OPTIMAL CELLULAR MASTS HOISTING OVER POPULATION COVERAGE
}

\author{
Tamaraebi Ambrose Enisuoh* and Okardi Biobele \\ Department of Computer Science and Informatics, Federal University Otuoke, P.M.B 126, \\ Yenagoa, Bayelsa State, Nigeria. \\ *Corresponding Email: tam4truth@yahoo.com
}

Cite this article:

Tamaraebi A.E., Okardi B. (2021), Implementation of Greedy Algorithm in Optimal Cellular Masts Hoisting Over Population Coverage. British Journal of Computer,

Networking and Information Technology 4(1), 68-78. DOI: 10.52589/BJCNITO5PVTEGT.

\section{Manuscript History}

Received: 12 June 2021

Accepted: 9 July 2021

Published: 26 July 2021

Copyright $\odot 2020$ The Author(s). This is an Open Access article distributed under the terms of Creative Commons AttributionNonCommercial-NoDerivatives 4.0 International (CC BY-NC-ND 4.0 ), which permits anyone to share, use, reproduce and redistribute in any medium, provided the original author and source are credited.
ABSTRACT: The need to meet the demands of subscribers of wireless services is imperative to Global System for Mobile (GSM) Communication companies. These demands, which revolve around the maintenance of good network coverage and improved Quality of Service (QoS), depend largely on the nature of cellular network masts. Greedy Algorithm Model was implemented on network masts for small size populated areas to effectively have optimal network coverage. Object Oriented Analysis and Design Methodology (OOADM) and Java programming language was used for its implementation. The analysis of the results shows that Greedy Algorithm performed optimizing cellular network masts hoisting optimally for small populated areas.

KEYWORDS: Greedy Algorithm, Population coverage, Optimal, Mast and Voronoi Diagram 


\section{INTRODUCTION}

Greedy Algorithm (GR) is an algorithmic paradigm based heuristic that follows local optimal choice at each step, with the hope of finding global optimal solutions for small populated areas. This algorithmic strategy makes the best optimal choice at each small stage with the goal of eventually leading to a globally optimum solution n. It builds a solution part by part, choosing the next part in such a way that gives an immediate benefit. This approach is mainly used to solve optimization problems.

In cases where the exact optimal solution is not obtained, it gives an approximate (near optimal) solution at a reasonable time. In addition, Greedy Algorithm is made up of five parts that include:

1. Candidate Set: This is where a solution is formulated.

2. Selection Function: This function determines the best candidate to be added to the solution.

3. Feasibility Function: It shows if a candidate can be used to contribute to a solution.

4. Objective Function: It assigns a value to a solution or a partial solution.

5. Solution Function: It shows when we have gotten a complete solution.

On the other hand, O'Flaherty (2001), who is a professional in legal Telecommunication, brought to the fore his own school of thought, that the result of proliferation of masts across our region is directly responsible for the increased need for television and mobile phone communications. Mobile masts, when erected, enable wireless communication with other available equipment such as phones, etc. which make available paths for wireless networks to communicate with other devices possible.

Furthermore, some papers written by scholars likened Telecommunication Masts to towers and Base Transceiver Station (BTS). The masts are in different shapes, forms, and sizes. Also, Mastsanity (2008) explained masts as big towers.

Zunia (2011) viewed mast as a location/place where antennas and electronic gazettes are designed to form a cell in a cellular network. According to Zunia (2011), based on the technology mast operators use, a mobile operator can hoist many base stations, each having its own function in that location.

\section{LITERATURE REVIEW}

Yosuke et al. (2011) worked on modelling and optimization of facility location and distribution planning problems. The focus of the problem is to get an optimal facility location based on management patterns with the application of large physical distribution on data. Here, transportation of facility location problems from office to sites and vice versa is looked at. When huge problems occur, Lagrangian relaxation is used to solve it.

Ren et al. (2008) presented an all-purpose bi-level simulated annealing algorithm (BSA) for facility location problems, to determine the demands of customers under the condition of 
minimum cost. This is dependent on the idea and character of the standard simulated annealing algorithm. From the researcher's findings, in solving the problem, the BSA was divided into two layers, namely inner and outer layers respectively. As a result, the outer algorithm is optimized and the inner algorithm is also optimized for allocation of customers' demand under the given decision of the outer algorithm.

\section{Research Methodology}

The researcher will develop the system using Object-oriented Analysis Design Methodology (OOADM). Object-oriented Analysis Design Methodology is a software engineering approach that models a system as a group of interacting objects. Each object represents a component of the system being modelled and is typically characterized by its state (data elements) and its behaviour. The behaviour of the system results from the collaboration between these objects.

\section{Data Flow Diagram of Greedy Algorithm}

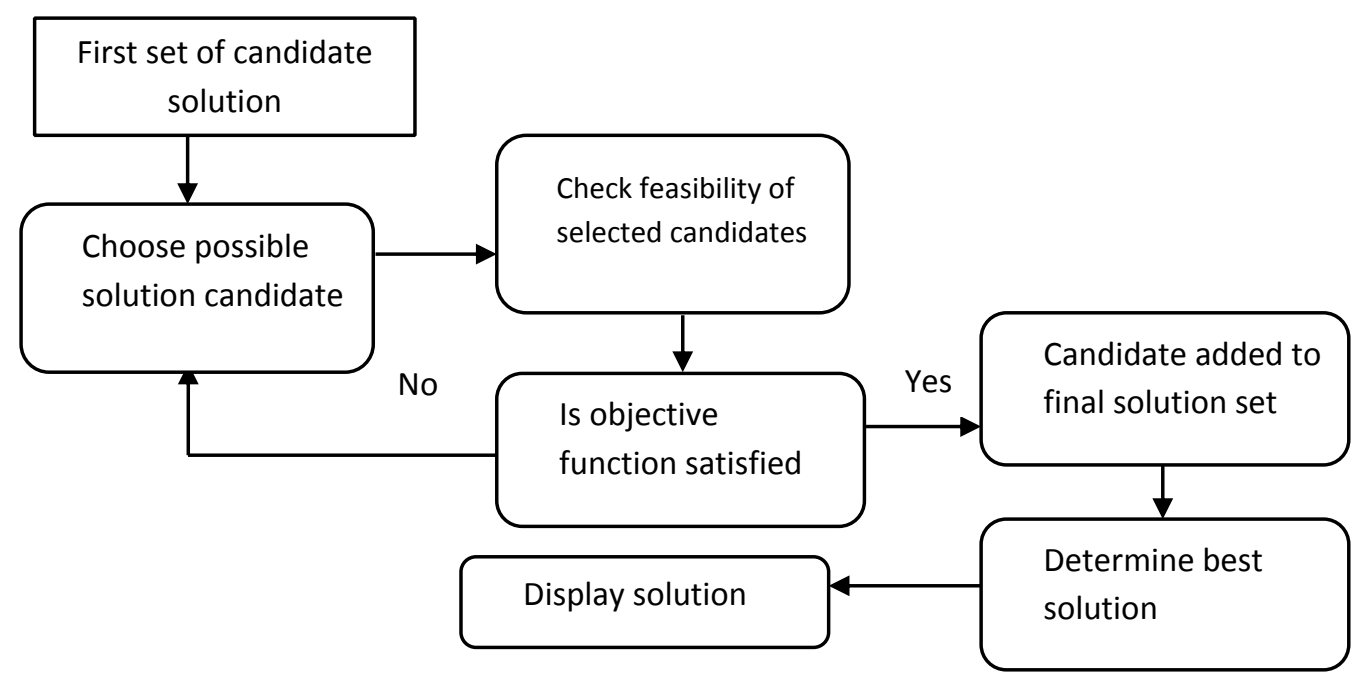

Figure 1.1: Data Flow Diagram of Greedy Algorithm

\section{Mathematical Model of Greedy Algorithm}

The mathematical model for the greedy algorithm is as follows:

$\mathrm{Sw}(\mathrm{F})=\{\mathrm{e} \in \mathrm{E} \backslash \mathrm{F} \mid \mathrm{w}(\mathrm{e})>0, \mathrm{~F} \cup \mathrm{e} \in \mathrm{F}\}(\mathrm{F} \in \mathrm{F})$.

where $\mathrm{S}$ is the initial set of elements and $\mathrm{F}$ is the final output containing the set of optimized elements. 


\section{The Pseudo-code of Greedy Algorithm}

1. Initialize: $F=$ null

2. Iterate: While $S_{\mathrm{w}}(\mathrm{F}) \neq$ null

2.1 Choose e $\in S_{\mathrm{w}}(\mathrm{F})$ of maximal possible weight w(e)

2.2 Update $\mathrm{F}=(\mathrm{F} \cup \mathrm{e})$

3. Output F.

\section{High Level Model of Greedy Algorithm}

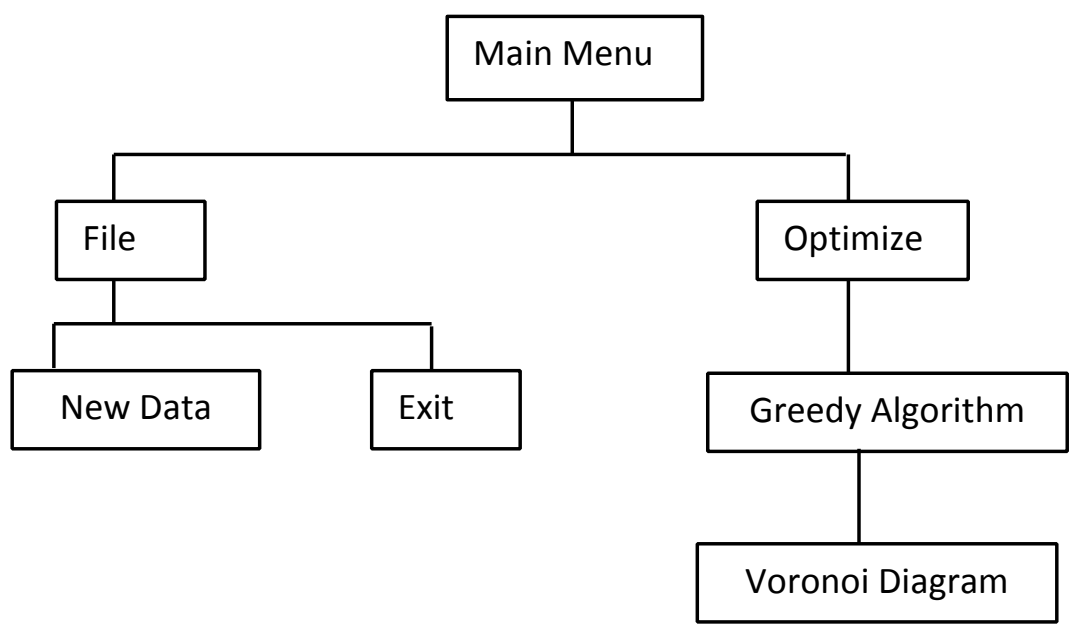

Figure 1.2: High Level Model of Greedy Algorithm

\section{Control Centre/Main Menu}

This section will provide a brief description of the menu and sub-menu items illustrated in the high-level model of Figure 3.3. Each category of menu items is discussed in the following subsections.

Two top-level items - namely File and Optimize — make up the main menu of the application.

File: This is made up of the menu options that handle the input of new data and exit.

Optimize: Greedy algorithm optimal test is performed in terms of the population covered using minimum number of masts hoisted.

New Data: Here, the number of regions and potential sites are specified, region data is specified with respect to the population size of each region and tower data for each tower is also specified. 
British Journal of Computer, Networking and Information Technology

ISSN: $2689-5315$

Volume 4, Issue 1, 2021 (pp. 68-78)

Exit: It terminates the application.

Greedy Algorithm: It does an optimality performance test.

Voronoi Diagram: It displays coverage area of sites.

\section{Class Diagram of the Greedy Algorithm}

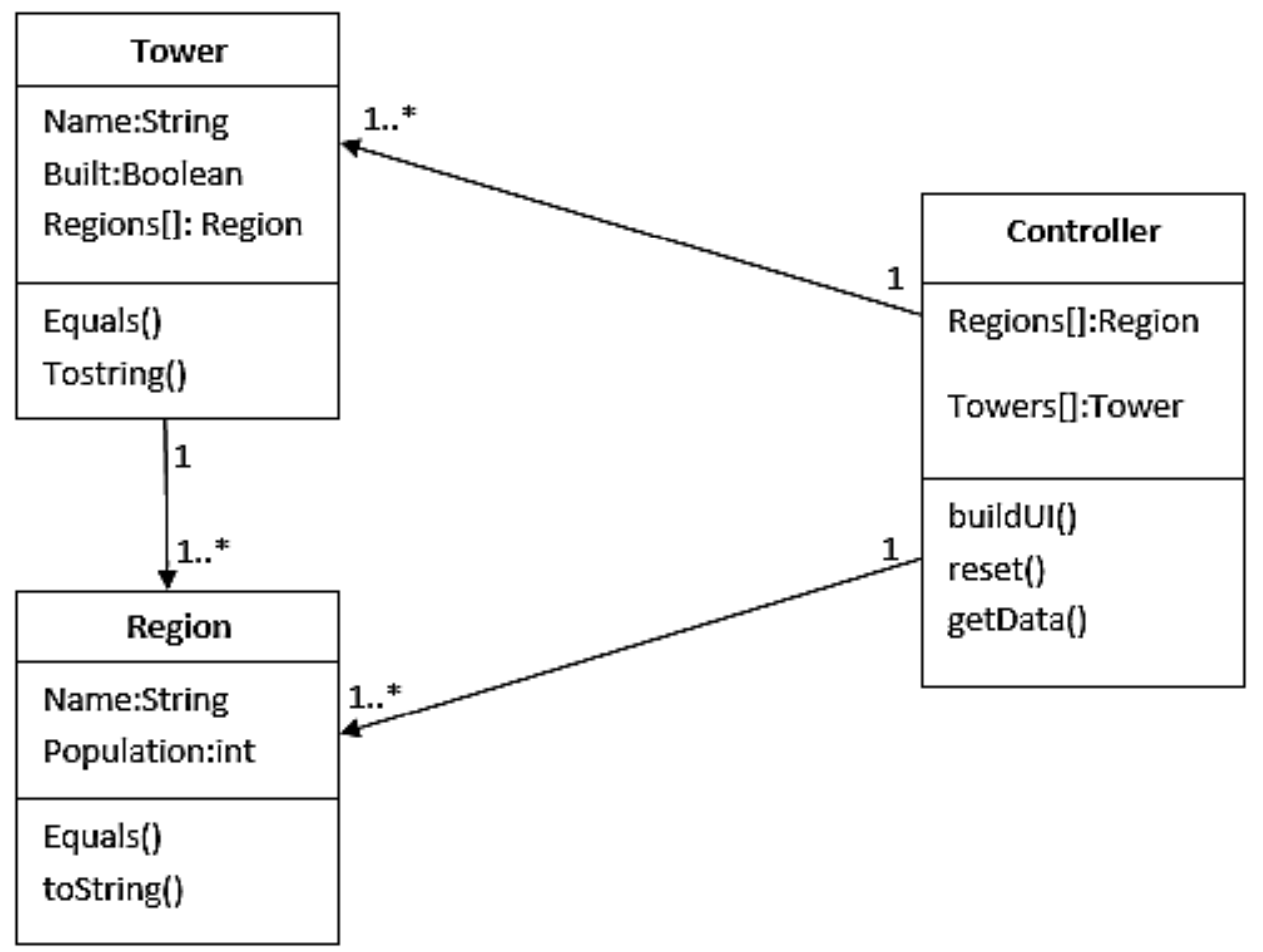

Figure 1.3: Class Diagram of Greedy Algorithm

Tower class: This class represents a potential location for the placement of a telecom mast.

Region class: This class represents a logical region, such as towns, in a local government area.

Controller class: The controller class encapsulates the Greedy Algorithm used to optimize the selection of location sites, handles the data input/output and the data flow between the various components of the system. 
British Journal of Computer, Networking and Information Technology

ISSN: $2689-5315$

Volume 4, Issue 1, 2021 (pp. 68-78)

Activity Diagram of Greedy Cellular Network Mast Hoisting

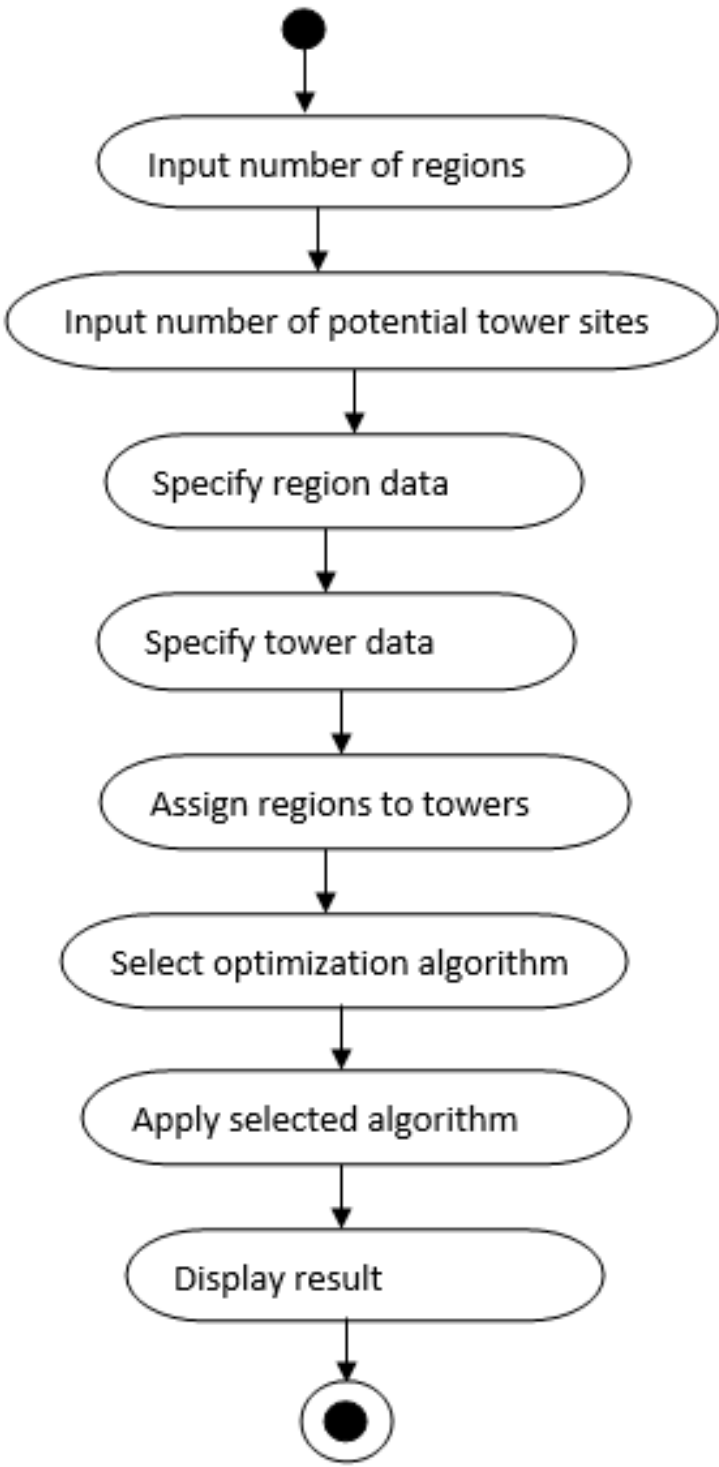

Figure 1.4: Activity Diagram of Greedy Cellular Network Mast Hoisting 
British Journal of Computer, Networking and Information Technology

ISSN: $2689-5315$

Volume 4, Issue 1, 2021 (pp. 68-78)

\section{Program Algorithm for Greedy Algorithm}

Begin

Specify the number of regions and possible cell towers/sites to be mounted

Validate specified number of cell towers

Enter population data values

Enter tower sites

Assign region data to tower site

Apply the selected algorithm to the data

Generate aggregate population covered

Using the selected tower sites, generate voronoi diagram

Terminate the application

End

\section{Test Results}

A highlight of the results is shown in Figure 1.4 to Figure 1.7.

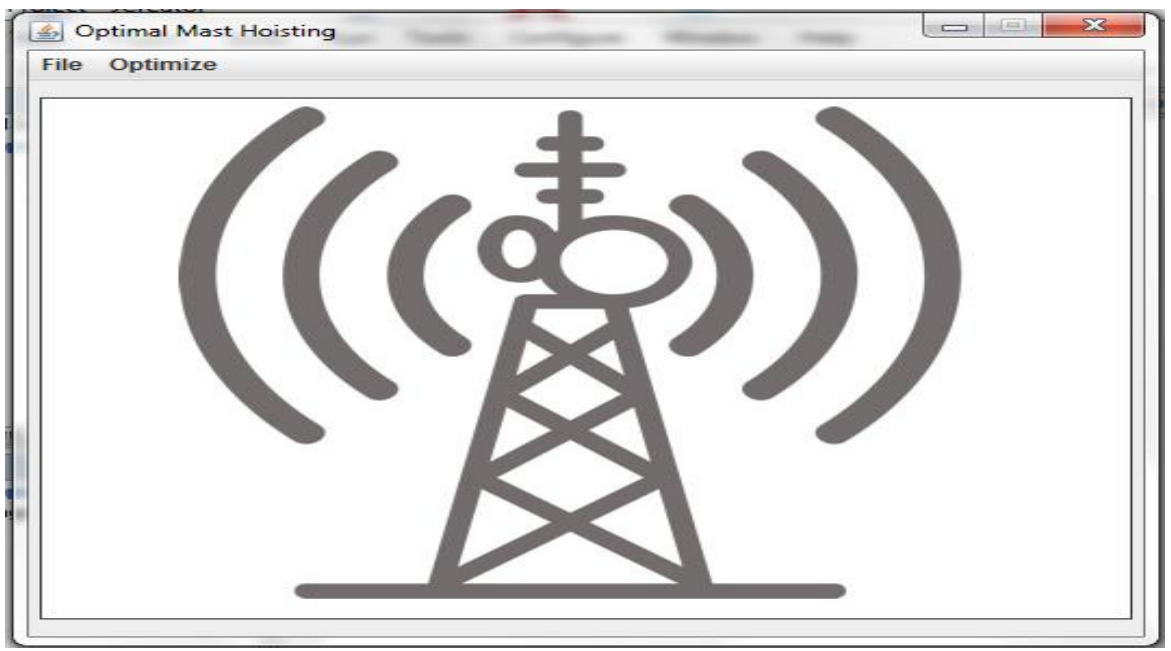

Figure 1.4: Home Screen of the System 
British Journal of Computer, Networking and Information Technology

ISSN: $2689-5315$

Volume 4, Issue 1, 2021 (pp. 68-78)

www.abjournals.org

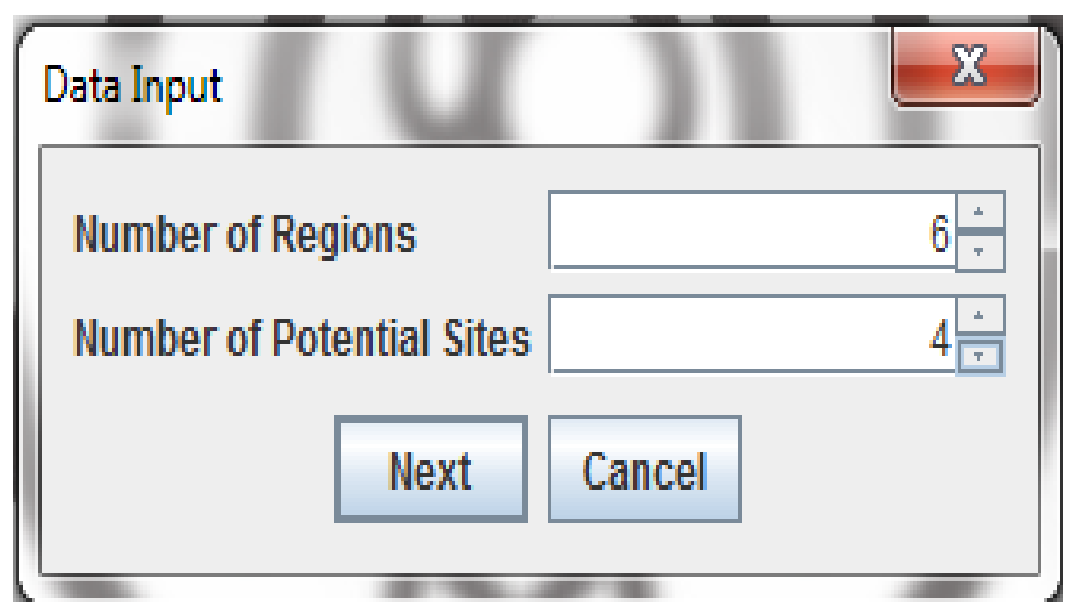

Figure 1.5: Data Input Screen of the System

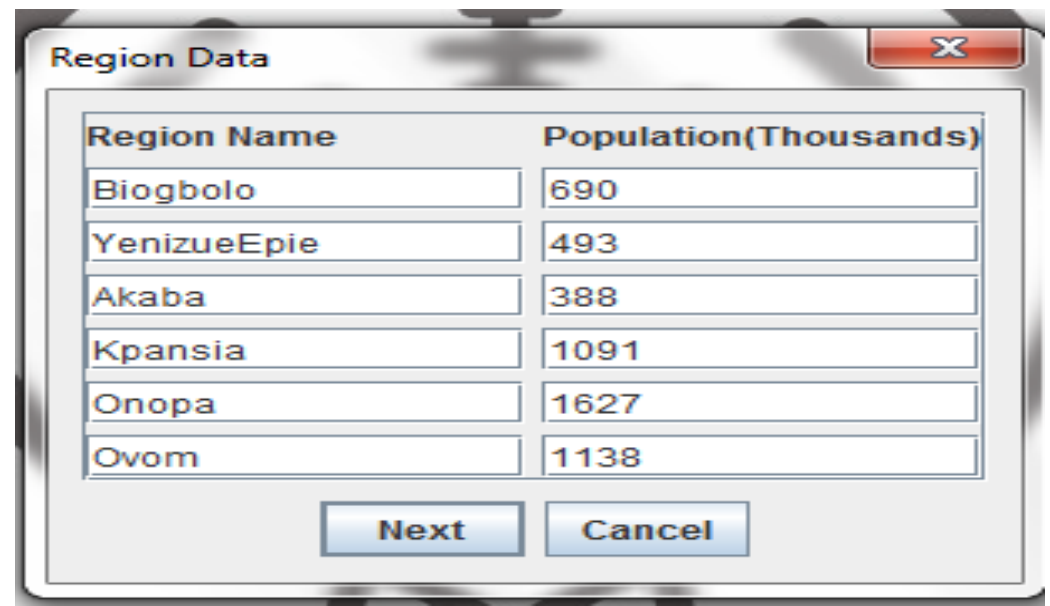

Figure 1.6: Region Data Input Screen of the System

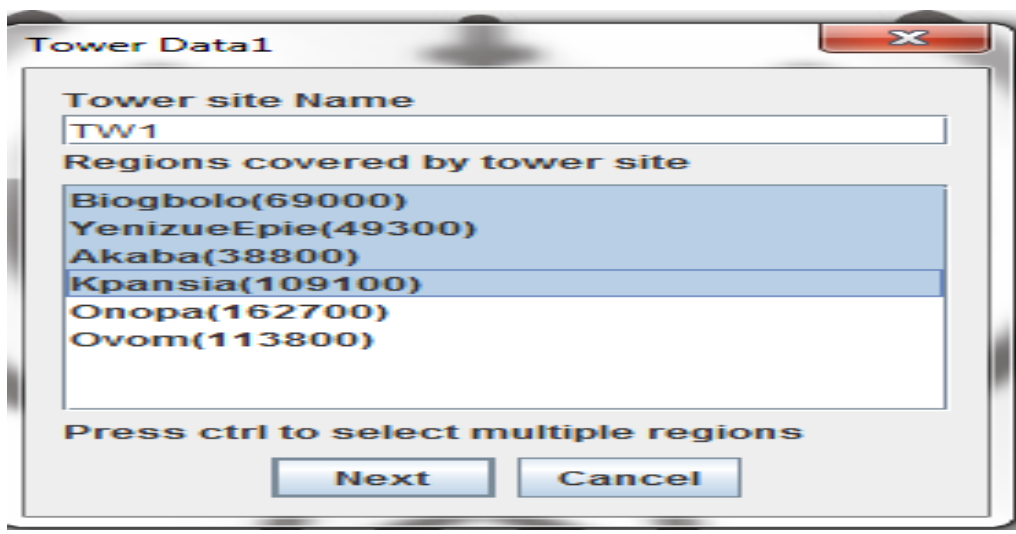

Figure 1.7: Tower Data Input Screen of the System 


\section{DISCUSSION}

Figure 1.4: The Home screen is displayed once the program is run to activate other modules under file and optimize menus.

Figure 1.5: Data input is carried out to specify the number of regions the mast is expected to cover and the number of potential sites meant for those regions.

Figure 1.6: Region data is generated with respect to the population size for each region.

Figure 1.7: Tower data is inputted for each tower earlier specified and multiple regions are highlighted/selected to show optimal coverage of the total population in the generated regions.

Figure 1.8: Shows the result of the Greedy Algorithm.

Figure 1.9: Shows the population coverage area of mast hoisted.

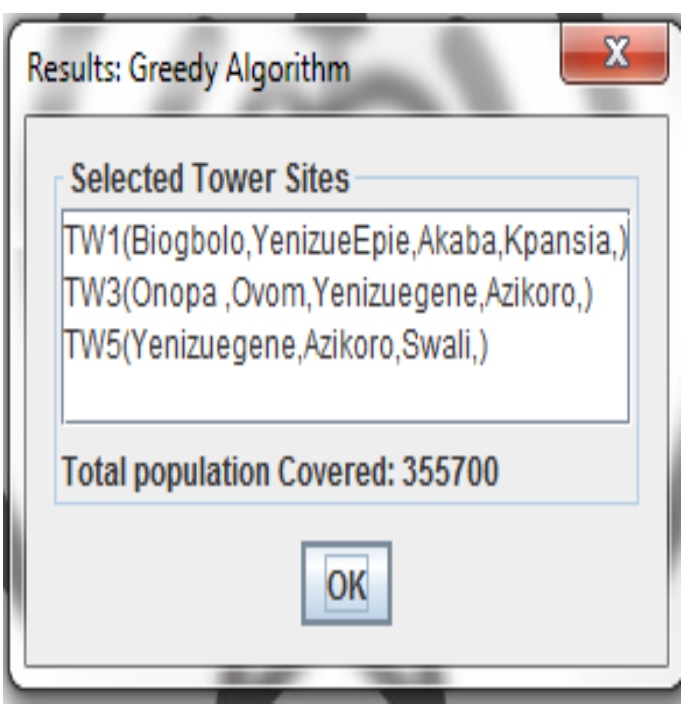

Figure 1.8

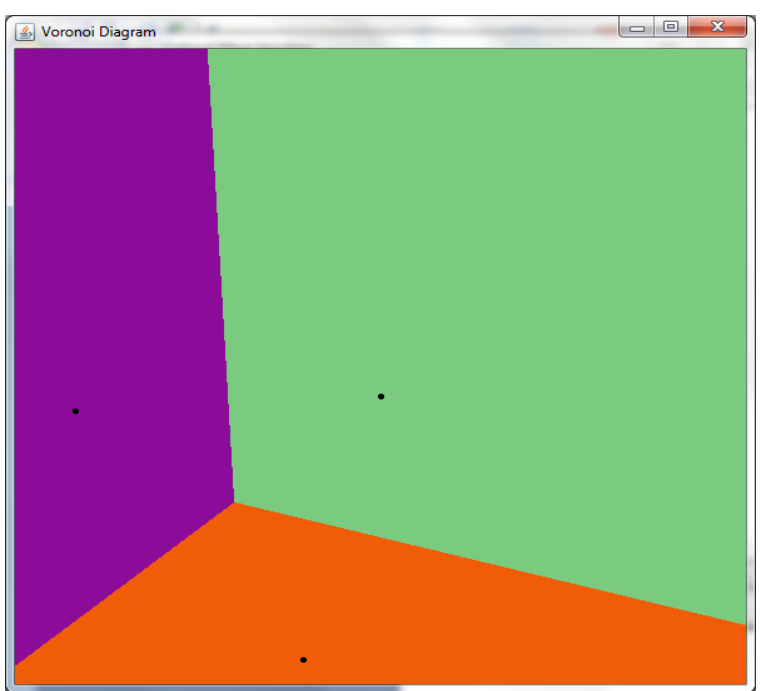

Figure 1.9: Voronoi Diagram 
Table 1.1: Performance Evaluation of Greedy Algorithm on Cellular Mast Hoisting Over

\section{Population Coverage}

\begin{tabular}{|c|l|l|l|l|}
\hline S/ & \multirow{2}{*}{$\begin{array}{c}\text { Numbe } \\
\text { r of } \\
\text { regions }\end{array}$} & $\begin{array}{c}\text { Number of } \\
\text { potential tower } \\
\text { sites }\end{array}$ & \multicolumn{2}{|c|}{$\begin{array}{c}\text { Selected sites } \\
\text { (Greedy Algorithm) }\end{array}$} \\
\cline { 4 - 5 } & & & $\begin{array}{c}\text { Towers } \\
\text { selected }\end{array}$ & $\begin{array}{c}\text { Aggregate population } \\
\text { covered }\end{array}$ \\
\hline 1 & 6 & 4 & TW1, TW3 & 231,700 \\
\hline 2 & 9 & 6 & $\begin{array}{l}\text { TW1, TW3, } \\
\text { TW5 }\end{array}$ & 355,700 \\
\hline
\end{tabular}

\section{Application Areas}

This research work can be applied in the following areas:

1. It can be applied in ad hoc mobile networking to efficiently route packets with the fewest number of hops and the shortest delay time.

2. It can also be used in Activity Selection Problems.

\section{CONCLUSION}

The essence of looking for optimal hoisting of cellular phone mast problems using computerbased algorithms is to provide a better quality of service and network coverage for users of cellular phone facilities, who need good service in order to carry out their day-to-day business transactions. In this work, Greedy Algorithm was looked at to handle the issue of optimal hoisting of cellular phone masts. The algorithm outputs a voronoi diagram to provide the basis for a computer-based solution to the problem of determining an optimal location for mast hoisting. This algorithm outputs the optimized number of cellular network masts to be hoisted, the exact towers that give the maximum/optimal network coverage and the voronoi diagram that shows the coverage area of sites.

\section{Suggestion for Further Research}

Analyze this Selection Greedy Algorithm with other types of Greedy Algorithms in respect to optimal hoisting of cellular phone masts, to know which one has the best coverage. 


\section{REFERENCES}

Atsuyuki Okabe, Barry Boots, Kokichi Sugihara \& Sung Nok Chiu (2000). Spatial Tessellations - Concepts and Applications of Voronoi Diagrams. 2nd edition. John Wiley.

Davood, S; Mahnam, M; Nookabadi, A.S (2008). "An efficient approach to discrete Multiple Different Facility Location Problem," Service Operations and Logistics and Informatics, IEEE International Conference, Vol.2, pp2519, 2524.

D'Roza, T., Bilchev, G. (2003). An overview of location-based services. BT Technology Journal, Vol. 21, No. 1 January 2003, pp. 20-27.

Fahham F. Cellular Communication Networks - GSM http://www.students.doc.ic.ac.uk/article.html

Gourdin, E., Labbe, M. and Yahan, H. (2002). Telecommunication and Location. In: Drezner $\mathrm{Z}$.

Harte L, Levine R, Livingston G (1999). “GSM Superphones”, McGraw Hill 71: 45-47.

Kashyap Rakesh, Malladihalli S Bhuvan, Srinath Chamarti, Pranav Bhat, Mintu Jothish and Karker Annappa (2014). Algorithmic Approach for Strategic Cell Tower Placement. Fifth International Conference on Intelligent Systems, Modelling and Simulation.

Laiho, J., Wacker, A., and Novosad, T., editors (2002c). Radio Network Planning and Optimisation for UMTS. John Wiley \& Sons, Ltd, 2nd edition.

Lee W.C.Y. (1995). Mobile Cellular Telecommunication - Analog and Digital Systems, 2nd Edition, McGraw-Hill, Inc. pg 189 - co-channel interference.

Mastsanity (2008). Mast Sanity Quick Guide To Mobile Phone Masts. Registered UK Charity no: 1109757.

Mumm, Michael. "Voronoi Diagrams," (2004). The Mathematics Enthusiast: Vol 1: No2,p.44-55.

National Bureau of Statistics (2015)

Optimization theory and Classical and New Gradient-Based Algorithms. Springer Science \& Business Media.

Snyman L. (2005). Practical Mathematical Optimization: An Introduction to Basic

Stallings, W. (2005). Wireless Communications and Networks. 2nd ed., New Jersey, Pearson Prentice Hall. 